\title{
Excess Shear Stress Analysis of Seismicity Associated With Dykes
}

\author{
J.V. James Celtis Geotechnical CC, South Africa \\ T. Rangasamy Celtis Geotechnical CC, South Africa \\ S.P. Petho South Deep Mine, Goldfields of South Africa, South Africa
}

\begin{abstract}
The design for mining the South Deep wide reef orebody was evolved from 1990 to 1997. When the regional stability pillars were laid out it was decided that to minimise loss of ore the Gemsbokfontein no. 2 dyke was included as the core of a $50 \mathrm{~m}$ wide pillar encasing the $25 \mathrm{~m}$ wide dyke. The dyke pillar was investigated using both elastic and inelastic numerical modelling. Assessment of the size of the modelled ESS lobes during the various stages of mining, led to the conclusion that a maximum magnitude seismic event up to 2.9 could have been expected on the dyke. This was only anticipated toward the end of mining.

Mining has subsequently occurred with the pillar left as designed. In July 2005 a 2.9 magnitude seismic event occurred on the dyke where it intersects another small dyke. Six seismic events with local magnitudes greater than 2 were measured in the pillar area over a 2.5 year period up to 2006. The distribution of seismic events indicates that major events were related to 2 smaller dykes intersecting the pillar.
\end{abstract}

A re-evaluation of the excess shear stress (ESS) on the planes of the three dykes was undertaken to assess the potential seismic risk.

The correlation between the maximum expected magnitude assessed from ESS modelling and actual magnitudes was remarkably good and also confirmed the original work completed in 1996.

The use of Boundary Element codes in predicting seismicity by ESS determination is remarkably accurate considering the simplicity of the codes.

On going modelling of this nature would be a useful tool for designing mining sequence and layout to ameliorate seismic activity and avoid working in seismically active mines.

During a period of more than a decade the use of ESS studies with elastic modelling to anticipate the location, timing and magnitude of seismicity has been successfully demonstrated at the South Deep Mine. This research showed that the seismicity experienced could be anticipated and that mine design can be modified to avoid seismic risk.

\section{Introduction}

The South Deep mine lies about $50 \mathrm{~km}$ south west of Johannesburg in South Africa. The mine exploits a tabular Witwatersrand conglomerate ore-body at depths between 2000 and $3000 \mathrm{~m}$ below surface. The orebody varies in width but over much of the area it consists of up to 4 conglomerate layers with an overall width of up to $50 \mathrm{~m}$. The orebody dips at about $15^{\circ}$. To allow cut-and-fill and drift-and-fill mining in the wide orebody the lowest thin reef of the orebody is mined by conventional scraper mining and backfilled. This reduces the stress regime in the wide orebody allowing pillars and large excavations to be mined with low seismic risk (James, 1998).

\subsection{Previous work}

The design for mining the South Deep, wide reef orebody was evolved from 1990 to 1997. First the concept of destressing the orebody by under stoping was finalised and several potential massive mining methods devised. It was understood that due to the depth and high percentage extraction of the planned mining, seismic activity would be expected. On this account several strategies were planned to minimise the amount of seismicity and its impact on the safety and efficiency of mining. The combination of backfill in the destressing mining, combined with regional pillars was planned to maintain the energy release rate (ERR) 
below a critical level of $30 \mathrm{MJ} / \mathrm{m}^{2}$ This value was chosen as a suitable value for design to limit seismicity in the geotechnical environment (Salamon, 1984). This would reduce the seismicity ahead of the stope faces by limiting the available potential seismic energy. It was also understood that seismicity could be generated on geological features and by the planned regional pillars. This could be assessed by numerical modelling of the size of lobes of excess shear stress (ESS) on the planes of the geological feature or the pillar edges, as suggested by Ryder in 1988.

The effectiveness of the prediction of seismicity using numerical modelling and the ESS and ERR techniques had not been verified or calibrated, so a process of back analysis was undertaken which entailed measuring the seismicity in the early mining around the shaft combined with closure measurement in the stoping and measurement of the upward movement of the 95 level haulage in response to the stoping The recorded seismicity was compared to the seismicity which would have been expected to be induced from calculation of ESS, and a good correlation was found. Similarly closure in stope was measured using closure meters and off reef movement was measured by levelling. These measurements were compared with the results of detailed numerical modelling of the area using 3D_Besol (Mining Stress Systems, 1997). The correlation between the measurements and the modelling was surprisingly good, in some cases within 5\% which increased the research team's confidence in the ability of modelling to predicted rock mass behaviour around the massive mining.

When the regional stability pillars were laid out it was decided that to minimise loss of ore the system should consist of dip or near dip pillars with the Elsburg massive shoreline (a paleo feature beyond which to the west the massive orebody is not developed) and the Gemsbokfontein no. 2 dyke as the primary features, and additional reef pillars where required to maintain the ERR criteria. The present pillar system is based on this scheme.

The Gemsbokfontein dyke was thus made the core of a $50 \mathrm{~m}$ wide pillar encasing the 25 to $30 \mathrm{~m}$ wide dyke. The stability of this pillar was of great concern for several reasons:

- The dolerite core of the pillar would concentrate stress.

- ESS would be developed on the dyke interfaces.

- Due to the wide orebody the pillar would not be sufficiently wide to fulfil the width to height criteria generally used for regional stability pillars.

The stability of the dyke pillar was thus investigated using both elastic and inelastic numerical modelling using FLAC (Itasca, 1992) modelling, and eventually it was concluded that the dyke would remain stable for the life of mining largely due to the constraining forces applied by the backfill which was to be placed in all the stoping against the pillar.

From the modelling, and assessing the size of the ESS lobes during the various stages of mining down to 95 level it was concluded that a maximum magnitude seismic event up to 2.9 could be predicted on the Gembokfontein dyke. However, it was concluded that it was more likely that a maximum of 2.5 event would occur, as it was considered that some of the potential energy would be dissipated in smaller seismic events. This was only anticipated toward the end of mining down to 95 level, it was planned that the effects of this seismic activity could be ameliorated by a mining sequence which moved away from the dyke early in the mining. This planning was done using the then preferred mining method which was cut-and-fill mining using 4 by $4 \mathrm{~m}$ drifts in a very strict sequence.

The same ESS studies also showed that events of magnitude 2.0 could be anticipated on faults parallel to the dyke at quite early stages of the mining. This was considered to be within the norm for deep level mining, and controllable by the use of rockburst resistant support, additional bracket pillars on faults and dykes, and very careful sequencing of the mining using seismic data.

At that time it was anticipated that the seismicity would be monitored from the early stages of mining, and that further work would be carried out to confirm or modify these early predictions. 


\subsection{Validation of the early work}

In July 2005 a 2.9 magnitude seismic event occurred located on the Gembokfontein dyke where it intersects the Grizzly dyke. Celtis Geotechnical was asked to remodel the present mining and the future mining sequence using MinSim 2000 (CSIR, 2000). From this it was possible to reassess the validity of the early planning process and to apply the ESS methodology to the Grizzly dyke. It could also assess whether the large event could have been anticipated using modelling of the mining sequence using ESS.

Once this was done it was possible to estimate the probability of future events of this size and greater during the mining process. This would enable the mine in future to:

- Assess the seismic risk, due to the events predicted.

- Consider methods to reduce the seismic risk by changing mining sequence and configurations.

\section{Mining layout relative to the dyke structures}

\subsection{Location and disposition of dykes}

The Gemsbokfontein No.2 dyke is a pervasive regional structure (Figure 1) at the South Deep Mine and strikes roughly north-south i.e. in line with the dip of the orebody. The dip angle of the dyke is close to $90^{\circ}$ and its width roughly $30 \mathrm{~m}$. The $1 \mathrm{~W}$ (east of dyke) stoping line is separated from the $2 \mathrm{~W}$ and $3 \mathrm{~W}$ (west of dyke) stoping lines by the Gemsbokfontein dyke.

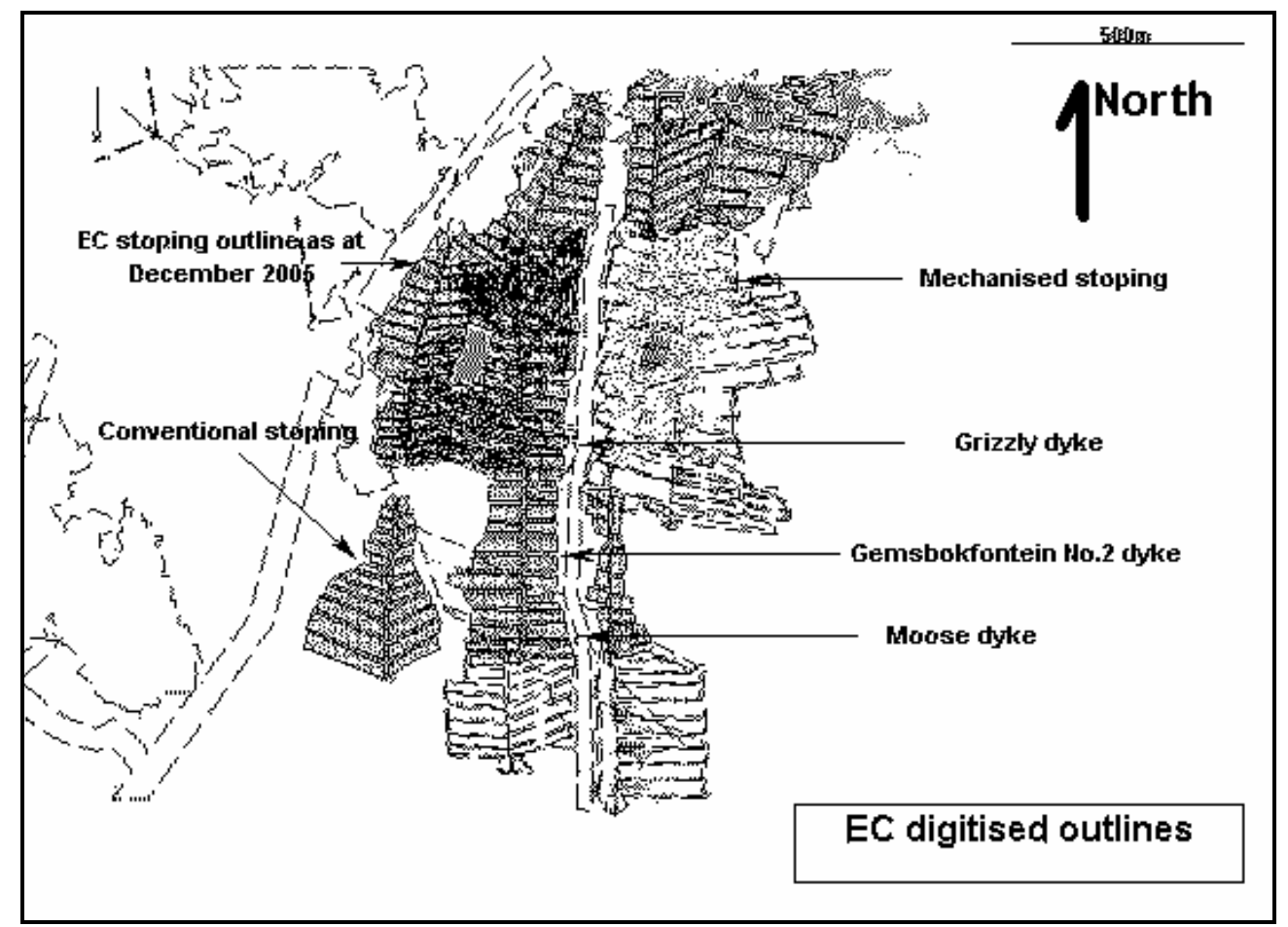

Figure 1 Dyke structures relative to the $1 \mathrm{~W}, 2 \mathrm{~W}$ and $3 \mathrm{~W}$ stoping lines - vertical projection

The Grizzly dyke strikes east-west (trace length along the strike of the orebody) and has a maximum width of $8 \mathrm{~m}$. This dyke was intruded earlier than the Gemsbokfontein dyke and is thus crosscut by the Gemsbokfontein dyke at approximately the elevation of 90 Level.

The Moose dyke is located south of the Grizzly dyke between 93 Level and 95 Level. The dyke dips at $67^{\circ}$ to the south. The dyke attains a maximum width of approximately $10 \mathrm{~m}$.

Both the Grizzly and Moose dykes are part of a dyke swarm that strikes east-west with at least 6 dykes being part of the initial swarm west of the EC shoreline. With progression east of the shoreline, the dyke swarm 
separates into two distinct dyke systems (Grizzly and Moose) that are separated horizontally by a distance of $340 \mathrm{~m}$ at the Gemsbokfontein dyke intersection.

\subsection{Stoping in the vicinity of the dykes}

The areal extent of stoping on either side of the Gemsbokfontein dyke is most extensive on the EC horizon, followed by the MB and MI/MA horizons. The undercut (destress cut) for massive mechanised mining has been interchanged between two different horizons of the Upper Elsberg orebody between 87 Level and 95 Levels. The variations in the location and extent of conventional undercut mining and massive mechanised mining was captured as accurately as possible during the digitising phase of the numerical modelling so that the determination of seismic magnitudes could be based on the realistic complex mining geometry rather than assumed mining extents for the various horizons forming the wide tabular orebody horizons. Additionally, the extent of VCR stoping west of the EC shoreline was accommodated in the models.

The total package thickness of ore horizons and middlings making up the orebody is approximately $38 \mathrm{~m}$.

\section{Historical seismic analysis}

A catalogue of 4829 seismic events of local magnitudes greater than -1 were retrieved from the mines seismic database and used to assess the current state of seismicity associated with the dyke structures. The seismic dataset included all recorded events between the period 20 September 2003 and 12 January 2006, i.e. approximately 2.5 years of data.

\subsection{Magnitudes greater than $\mathrm{M}_{\mathrm{L}}=\mathbf{1 . 5}$}

A list of seismic events greater than and equal to 1.5 were filtered from the list and plotted on a composite mining plan (Figure 2) to assess the clustering of 'large events' in relation to the dyke structures.

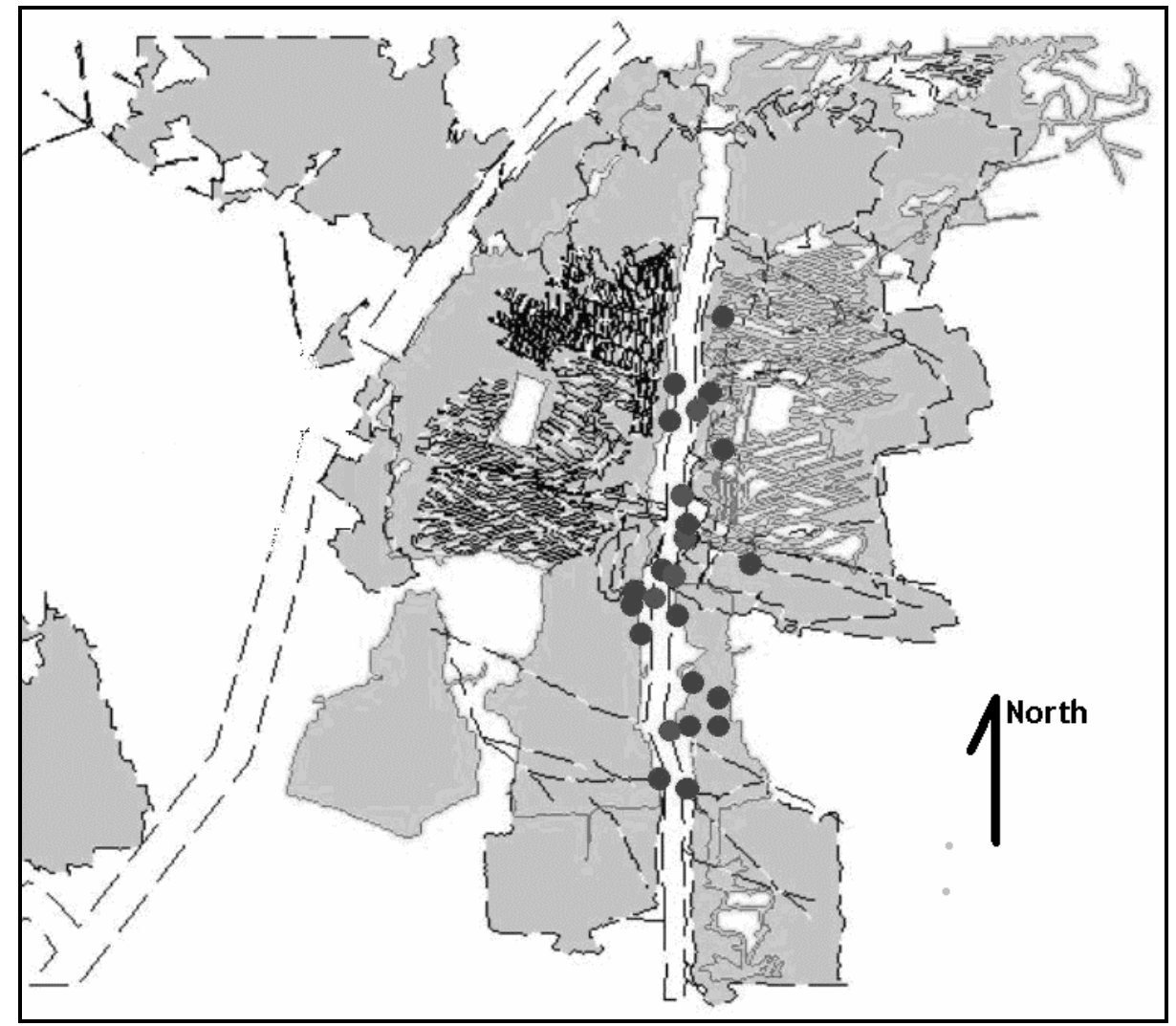

Figure 2 Seismic events greater than $M_{L} 1.5$ for the $1 \mathrm{~W}, 2 \mathrm{~W}$ and $3 \mathrm{~W}$ stoping lines (Sep 2003-Jan 2006) 
The following conclusions can be drawn from the spatial assessment of the seismic events:

- About $80 \%$ (19 of 24 events) of the seismic events lie directly on the line of the Gemsbokfontein Dyke.

- 5 of the 6 seismic events with magnitude greater than 2 lie in close proximity (close enough to be within the accuracy of the seismic system) to the Grizzly and Moose dykes.

- The largest magnitude recorded $\left(\mathrm{M}_{\mathrm{L}}=2.9\right)$ was located at the area where the Grizzly dyke intersects the Gemsbokfontein Dyke.

- All seismic events greater than $\mathrm{M}_{\mathrm{L}}=2$ lie on the $1 \mathrm{~W}$ side of the Gemsbokfontein Dyke. This was based on spatial data and does not account for location errors.

- $\quad$ The position and depth below surface of the 24 large events show that events greater than $\mathrm{M}_{\mathrm{L}}=2$ tend to be associated with areas where the Grizzly and Moose dykes intersect the Gemsbokfontein Dyke.

\subsection{Gutenberg-Richter distribution}

The Gutenberg-Richter (GR) relationship that describes the frequency-magnitude distribution of small and intermediate size seismic events was plotted (Figure 3) for the full event listing within 0.2 magnitude ranges to determine a likely largest possible event size $\left(\mathrm{M}_{\max }\right)$.

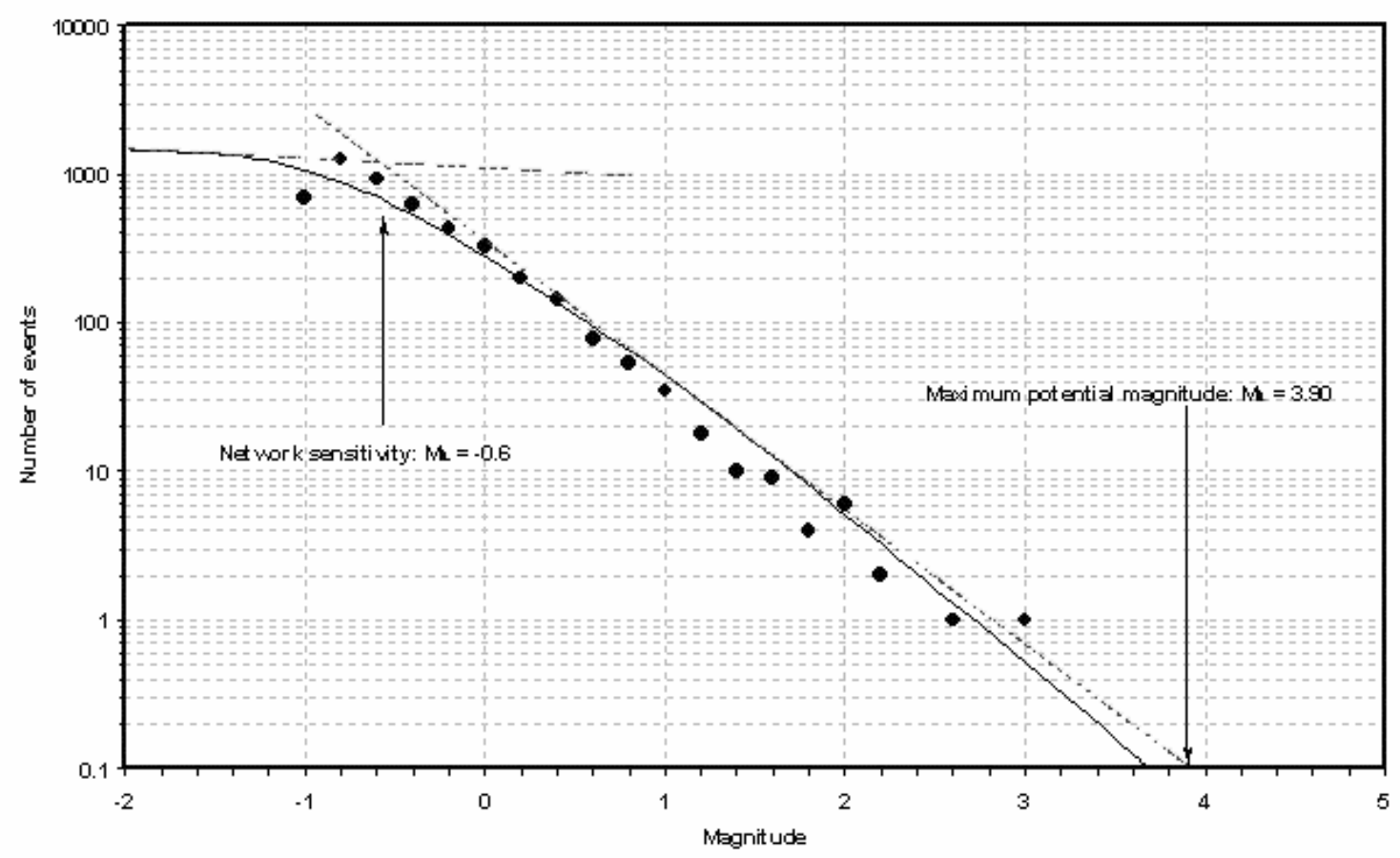

Figure 3 Gutenberg-Richter density distribution of events for the 1W, $2 \mathrm{~W}$ and $3 \mathrm{~W}$ stoping lines (each dot represents the number of events measured within a 0.2 magnitude range)

On extrapolation, a likely maximum possible magnitude of $\mathrm{M}_{\mathrm{L}}=3.90$ is indicated by the data. Such an event size will most probably be associated with the dyke structures rather than pillar failure. The $\mathbf{M}_{\max }$ obtained was used as a benchmark for the output of the numerical models by defining a maximum limit on the expected seismic events in the system, derived from measured data for comparison with the calculated values. 


\section{$4 \quad$ Numerical analysis of seismicity associated with the dyke structures}

The numerical modelling was undertaken using the linearly elastic MINSIM 2000 package. Input properties for the models are listed in Table 1. The mining grid was simulated using element or grid sizes of $6 \mathrm{~m}$ for all reef horizons. Benchmark windows were placed on the plane of the reef bands that define current and subsequent mining and on the plane of the Gemsbokfontein Dyke, Grizzly and Moose dykes.

Six model variations were set-up using the base case MINSIM modelling state digitised from the mine plans. A lengthy and rigorous test phase was performed to ensure that models remain stable for the multi-reefs being simulated. Several models were set-up and eventually the one depicting the likely intermediate and final state mining layout was comprehensively assessed.

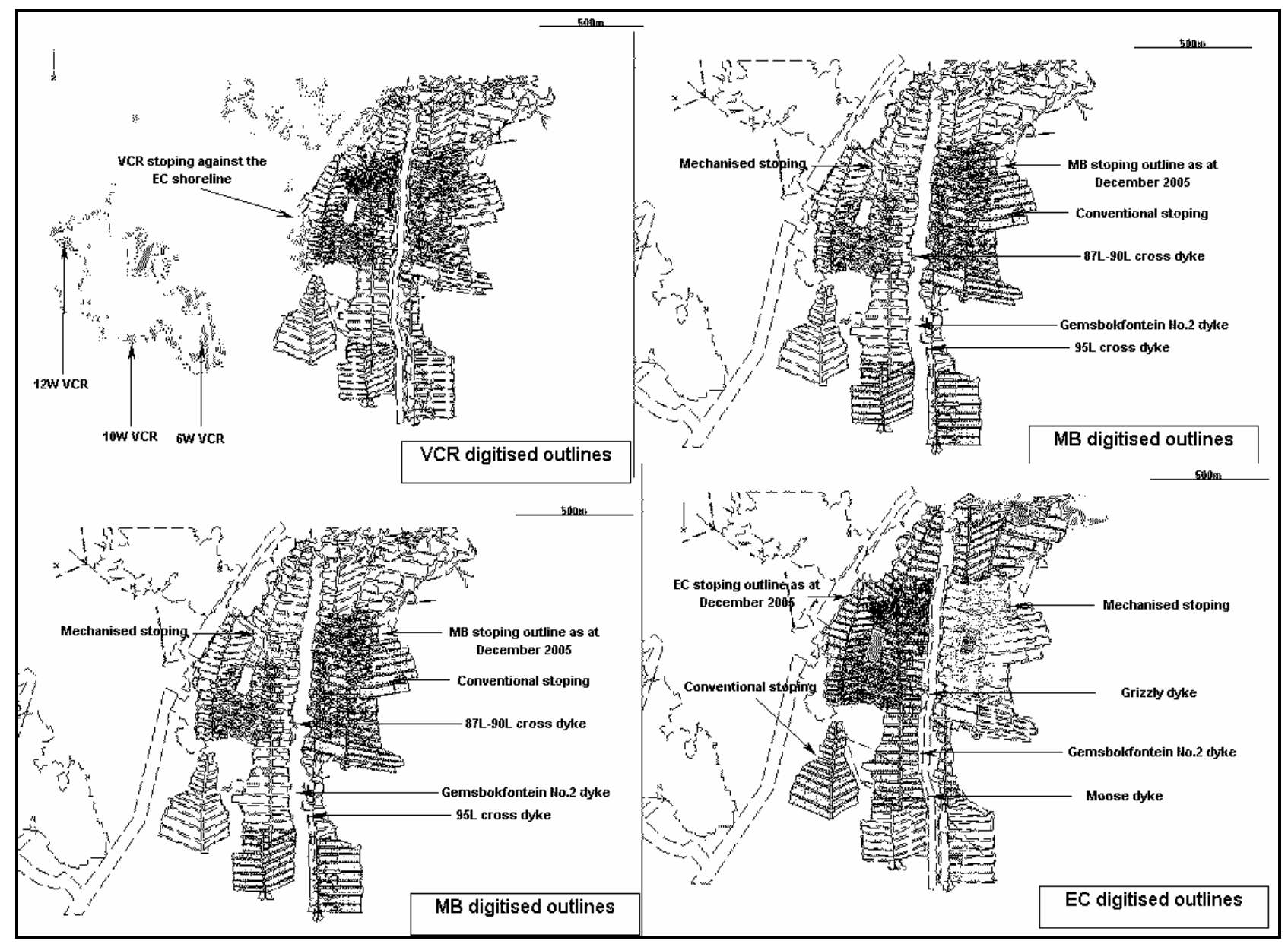

Figure 4 Outlines of the four mined reefs as modelled

\subsection{Incorporation of the effect of backfill in the numerical modelling}

A standard hyperbolic model used for classified tailings backfill in tabular stopes was applied in all destress mining cuts. The area filled ranged between $60-70 \%$ of the mined area. A hangingwall to backfill placement gap of $5 \mathrm{~cm}$ was assumed in the modelled. Backfill was placed concurrent with the mining step. 
Table 1 Input parameters used in Minsim models

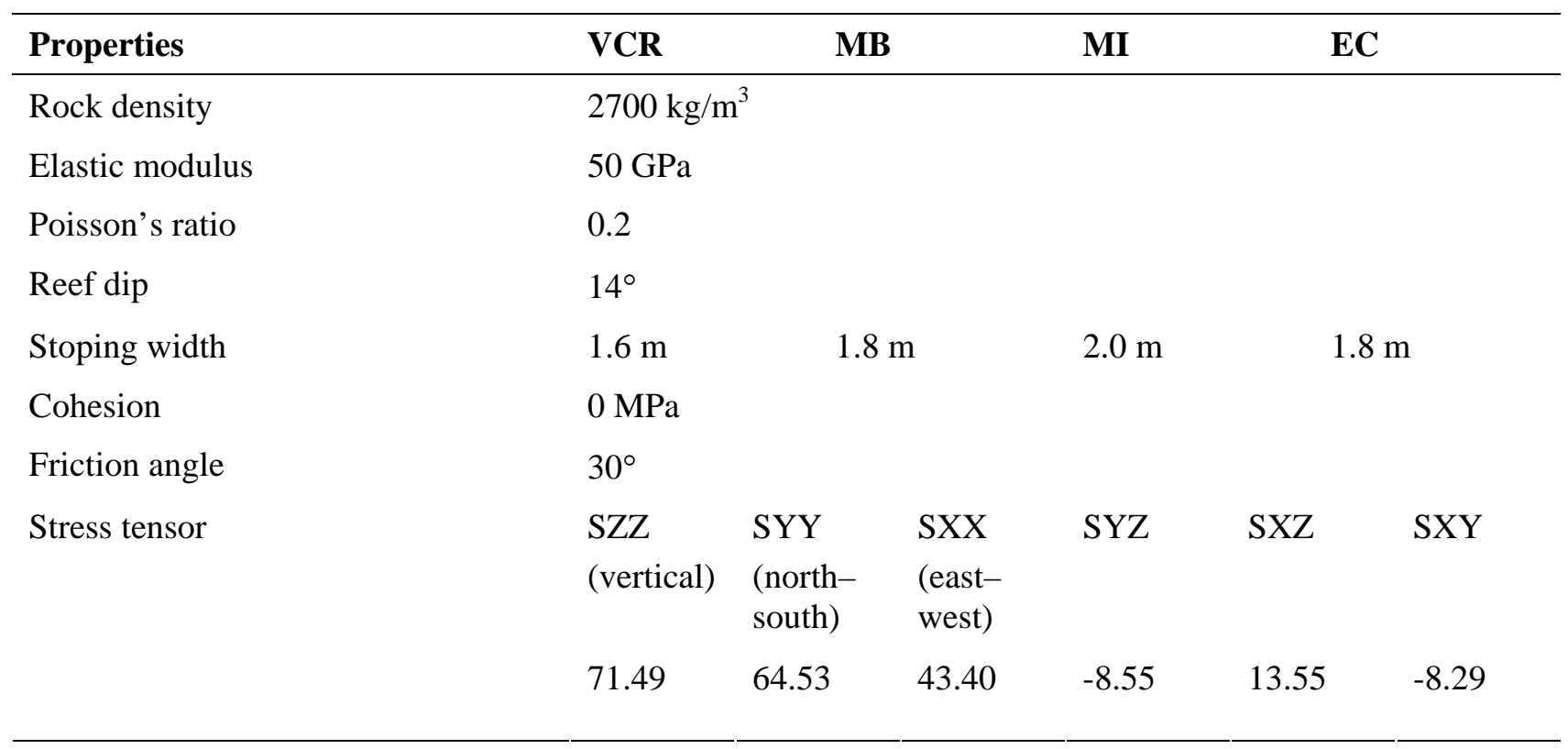

\subsection{Excess shear stress (ESS) methodology}

The Excess Shear Stress (ESS) was recorded on the geological structure and assessed by estimating the seismic moment from the size of the ESS lobes and thence calculating magnitudes.

The Gemsbokfontein Dyke, Grizzly and Moose dykes were modelled as off reef benchmark sheets (implicit representation). The possibility of seismic events can be estimated using the excess shear stress criterion of Ryder (1988). The excess shear stress was calculated on the benchmark sheet using a friction angle of $30^{\circ}$ and cohesion of zero. The dimensions of ESS lobes were estimated using the contour of ESS values greater than $0 \mathrm{MPa}$. As the ESS lobes are oval shaped in the plane of the structure, the seismic moment can be estimated with the formula:

$$
M_{o}=2 a^{2} l \tau_{e \max }
$$

The parameter $\tau_{e \text { max }}$ is the maximum ESS, $\boldsymbol{a}$ is the positive ESS lobe width and $l$ is the lobe length. The equivalent moment magnitude can be estimated using the formula:

$$
M_{L}=\frac{\left(\log M_{o}-9.1\right)}{1.5}
$$

Where $\mathrm{M}_{\mathrm{o}}$ is in Pa (or, units of pressure).

This method does not consider the release of energy by previous events and subsequent redistribution of stresses. It also does not consider the effect of any residual stresses induced in the rock mass due to the relative displacement of the reef across the fault and the dykes. The current modelling method does not account for variations in friction angles, cohesion or stress along the contact plane of the structure analysed.

A factor of eight instead of two was used in equation 2.1 for the Grizzly and Moose dykes since these potential rupture planes daylight against the EC and MB stopes.

A $2 \%$ seismic efficiency was used to discount modelled moments since it is a well-known postulate (McGarr and Weibols, 1977) that roughly $2 \%$ of energy is released to form seismic events and the rest is dissipated in heat and the fracturing process. 


\section{Results}

Since more than one positive ESS lobe is created on the plane of the off-reef benchmark sheet, the moments and magnitudes were calculated for each individual lobe. Where lobes merge with the progression of mining steps, the resulting moments and magnitudes were calculated for the single lobe. Where more than one lobe exists, the maximum modelled magnitude for any given lobe is compared to the seismic record.

\subsection{Modelled versus actual magnitudes}

The correlation between magnitudes estimated from modelling and actual magnitudes is remarkably good which indicates that regionally:

- The rock mass behaves elastically.

- The input parameters are sound and applicable, in particular the stress tensor since this parameter has the most influence on ESS.

Table 2 shows the maximum seismic magnitudes derived from the seismic listings compared to the maximum potential magnitudes derived from the numerical models.

Table 2 Modelled versus actual and Gutenberg-Richter projected seismicity

\begin{tabular}{lcccc}
\hline $\begin{array}{l}\text { Geological } \\
\text { structure }\end{array}$ & $\begin{array}{l}\mathbf{M}_{\text {max }} \text { modelled for } \\
\text { current state }\end{array}$ & $\begin{array}{l}\mathbf{M}_{\text {max }} \text { recorded } \\
\text { magnitude }\end{array}$ & $\begin{array}{l}\mathbf{M}_{\max } \\
\text { Gutenberg- } \\
\text { Richter }\end{array}$ & $\begin{array}{l}\mathbf{M}_{\max } \text { final } \\
\text { modelled state }\end{array}$ \\
\hline $\begin{array}{l}\text { Gemsbokfontein } \\
\text { No.2 dyke }\end{array}$ & 2.02 & $\begin{array}{c}2.1 \text { (2.9 and 2.5 } \\
\text { at Grizzly and Moose } \\
\text { intersections) }\end{array}$ & 2.62 \\
Grizzly dyke & 2.94 & 2.9 & $\begin{array}{c}3.9 \text { (the } \mathrm{M}_{\max } \\
\text { was calculated } \\
\text { for the entire } \\
\text { database) }\end{array}$ & 3.32 \\
Moose dyke & 1.78 & 2.5 & & 4.22 \\
& & & & \\
\hline
\end{tabular}

\section{Discussion}

\subsection{General}

The numerical modelling indicates that very good correlation with actual seismicity can be obtained using elastic numerical modelling and ESS studies. In fact it would have been possible to have predicted the position and maximum potential magnitude of the seismic events on the Grizzly dyke intersection and on the Gemsbokfontein, had ESS studies been carried out on the current mining prior to the event. The Numerical modelling and ESS studies cannot however calculate the effect on the seismic activity of the interaction of the whole 3 dimensional system, thus although the maximum potential event on any specific plane can be calculated, the effect of one large event on the energy available on the whole dyke system cannot be assessed.

It seems that none of the ESS was dissipated in minor seismicity or more likely that the seismic efficiency is greater than $2 \%$, however this is simplistic, as pointed out above the interaction of shear stresses of the 3-dimensional system cannot be calculated. However in an empirical way the methodology seems to have some ability to assess seismic potential.

The accuracy of the modelling in geometry sequence and input parameters especially stress tensors are vital if valid results are to be obtained. This is shown by the sensitivity of the potential seismicity on the Moose dye to its orientation to the stress tensor. Usable results as shown above cannot be obtained without proper back analysis to validate rock mass properties, and meticulous numerical modelling.

The correlation of seismic events and ESS predictions are sufficiently close that the ESS work justifies taking measures to reduce the potential hazard, where possible. These measures given the current extent of 
mining are quite difficult to formulate but as discussed below the planning of bracket pillars on the Moose Dyke is a priority as extremely large potential events are indicated on that feature.

\subsection{Previous work}

The ESS work done in 1995 and1996 correlates well with the seismicity encountered on the Gemsbokfontein and other dip parallel features. The original work even postulated a 2.5 magnitude event on the Gemsbokfontein pillar based on a then calculated 2.9 event. The prediction that the large events would occur late in the life of mine was based on a mining sequence very different from the current mining. The sequence was specifically designed to mine away from the dyke pillar.

The more recently modelled work includes calculation of the ESS on the Grizzly and Moose dykes which were not part of the original modelling. The 2.9 magnitude event which correlates with the measured event in was calculated from the ESS on the plane of the Grizzly dyke and not the Gemsbokfontein

Despite all the above, the agreement between the current work and the early work is good and at no point are the results contradictory.

\subsection{Gemsbokfontein Pillar}

The Gemsbokfontein dyke pillar has had several 2 magnitude events and the ESS lobes calculated indicate that a 2.6 magnitude seismic event is the maximum anticipated. This essentially agrees with the previous work and implies that the pillar is stable and no increase in seismicity over the present level is anticipated.

\subsection{Grizzly Dyke}

A 2.9 magnitude seismic event was predicted by the ESS study and an event of this magnitude occurred in July 2005. With the final mining configuration, a maximum 3.3 magnitude event is predicted but as the 2.9 magnitude event has already occurred, the available energy may have been dissipated. It is anticipated that as mining continues, further 2+ magnitude events can be anticipated on the Grizzly. It was suggested that the mining sequence should be planned to mine out the area adjacent to the Gemsbokfontein and the Grizzly as early as possible.

\subsection{Moose Dyke}

The ESS study indicates that the Moose dyke currently has a potential for a 2.0 event, but this will increase very rapidly when the 951 west and 2 west are mined out. The predicted maximum magnitude event is 4.2. It is felt that this will probably not occur but several $\sim 3$ magnitude events can possibly be anticipated.

It was strongly recommended that portions of the reef about the Moose Dyke at the intersection with the Gemsbokfontein dyke pillar should be left un-mined to act as bracket pillars. In this way the seismic potential could be limited.

It is not known if the events which have occurred along the Gemsbokfontein have dissipated the energy available to drive seismicity on the Moose dyke. It is expected that the energy is inter-related between the structures but this cannot be analysed using ESS.

\subsection{Other dykes and faults}

Scrutiny of the position of the larger magnitude events about the Gemsbokfontein pillar indicates that they cluster on east west trending features intersecting the pillar. These features were not analysed in this study. However it is certain that the ESS results would be similar for any feature with similar geometry. The high stress on the dyke pillar seems to drive the shear stresses on the east west trending features.

Seismicity on these features should be anticipated. The magnitudes of such events would depend on the orientation and the mining configuration. 


\section{Conclusions}

The use of detailed elastic modelling for the calculation of the potential positions and magnitudes of seismic events has been shown to have considerable success in the two modelling exercises discussed in this paper. It is understood that the methodology cannot analyse the complex 3-dimensional shear stress environment, however the analysis of ESS on individual planes representing geological features has produced valid and repeatable results. It is believed ongoing modelling of this nature would be a useful tool for designing mining sequence and layout to ameliorate seismic activity and avoid working in seismically active mines.

The accuracy of the modelling in geometry sequence and input parameters especially stress tensors are vital if valid results are to be obtained.

More specifically during a period of more than a decade the use of ESS studies with elastic modelling to anticipate the location, timing and magnitude of seismicity has been successfully demonstrated at the South Deep Mine. This latest research showed that the seismicity experienced could be anticipated and that the mine design can be modified to avoid seismic risk.

\section{References}

Council for Scientific and Industrial Research (CSIR) (2000) MinSim 2000 (http://www.minemodel.co.za/minsim.asp).

Itasca Consulting Group, Inc. (1992) FLAC2D: Fast Lagrangian Analysis of Continua. FLAC, 3.2 Users Manual. Itasca Consulting Group, Inc.

James, J.V. (1998) Geotechnical influences upon the design and operation of a deeplevelwide orebody gold mine. PhD thesis submitted to the University of Wales, College of Cardiff.

McGarr, A. and Weibols, G.A. (1977) Influence of mine geometry and closure volume on seismicity in a deep level mine. International Journal of Rock Mechanics Mining Science and Geomechanics, Abstracts Vol. 14.

Mining Stress Systems (1997) Users guide for BESOL/MINAP_97 for Windows:Minining Applications for Boundary Element Methods, Version 1.00. Mining Stress Systems (Pty) Ltd. Johannesburg

Ryder, J.A. (1988) Excess shear stress in the assessment of geologically hazardous situations. Journal of South African Mining and Metallurgy, Vol. 88 (1), pp. 27-39.

Salamon, M.D.G. (1984) Energy considerations in rock mechanics; fundamental results. Journal of South African Mining and Metallurgy, Vol. 78 (1), pp. 27-39. 